\title{
Multifunction Finishing and Pigment Printing of UV Cured Cotton/Polyester Fabrics Coated with Plasticized Epoxy Resin/ZnO Formulation
}

\author{
M. S. Hassan, I. M. Mousaa and N. M. Ali
}

Radiation Chemistry Department, National Centre for Radiation Research and Technology (NCRRT), Atomic Energy Authority, B.O. Box 29 Nasr City, Egypt.

\footnotetext{
COTTON/ POLYESTER fabrics were coated with epoxy acrylate (EA) formulations plasticized by castor oil (CO), in the presence of benzophenone as initiator, $\mathrm{ZnO}$ (antibacterial agent) and pigment printing. Ultra violet (UV) irradiation was used as a curing system. The effect of UV irradiation time and $\mathrm{CO}$ percentage on the mechanical and crease recovery properties were investigated. The effect of the coating process on the cross-section feature by using scanning electron microscope (SEM), the antibacterial properties, water retardance, colour difference and the durability for washing of the coated fabrics were also investigated. From the results, it was found that the crease recovery and antibacterial properties were enhanced. Also, the colour durability against multiple washing cycles gave adequate results after application of the investigated coating formulation. The most fitting castor oil per cent was found to be $45 \%$, while the $3 \% \mathrm{ZnO}$ recorded the best antibacterial and mechanical properties. The pigment per cent that gave the highest durability and adequate colour strength was $0.6 \%$.

Keywords: Epoxy acrylate, castor oil, UV radiation, antibacterial, printing, water retardant.
}

UV radiation curing is a technique widely used to converts a reactive monomer into a solid through photo-polymerization and crosslinking reactions. UV radiation allows the preparation of transparent coatings with good properties (Decker, 2003). The widespread interest for UV systems can be explained by several reasons such as their rapid polymerization, which can be controlled by light intensity, and their very low energy consumption. Moreover, UV curing technology allows low temperature operation, application versatility and good viscosity control. 
This technology is also very attractive from the environmental point of view since no organic solvents are required. Polymers cured by UV light usually exhibit superior mechanical, chemical and heat resistance because of their higher cross-linking density (Landry et al., 2008). Epoxy acrylate resin is the classic resin for UV curing coatings because of its good integrated performance such as outstanding adhesion, non-yellowing, hardness and chemical resistance (Bayramoglu et al., 2006) and thus wide applications. Epoxy acrylate resins generally are high viscosity reactive oligomers due to the strong hydrogen bonding through secondary hydroxyl groups (Oprea et al., 2000) and produce hard, glossy and chemical resistance coating. Due to rigid and brittle nature, epoxy resins exhibit low toughness, and poor wear and crack resistance in a real application (May, 1988). To overcome these problems, a considerable amount of work has been carried out focusing on introducing rubbery and flexible components into epoxy networks (Park et al., 2001). On the other hand, flexibility of epoxy acrylate resin can be modified by adding non-reactive plasticizer such as (vegetable oils, polyesters and polymerizable celluloses) (Ibrahim et al., 2011).

Vegetable oils are non-toxic, non-depletable, domestically abundant, nonvolatile and biodegradable resource and they find innumerable industrial applications such as plasticizers, biodiesel, lubricants, adhesives, biodegradable packaging materials, printing inks, paints and coatings (Salimon et al., 2012). Castor oil is an inexpensive, environmental friendly, renewable and a naturally occurring vegetable oil with low toxicity and has free secondary hydroxyl groups (Palanisamy et al., 2007).

Castor oil has an overall hydroxyl functionality of about 2.7 and used for plasticized epoxy acrylate resin films (Mortley et al., 2007). Different properties of plain weave fabrics for desired application can be achieved by using the coating techniques with curable formulations. As examples: The antipilling characteristic, antibacterial activities and was applied by coating with Polyurethane acrylate copolymer (PAC) (Tabasum et al., 2013), the pigment colouring of cotton fabrics by coating from one surface with different formulations containing ethylene glycol (EG), methyl methacrylate (MMA) and poly(methyl methacrylate) (PMMA) oligomer as a base material was studied (ElNaggar et al., 2005). The ink jet printing and pigment dyeing of cotton, viscose, wool, polyester and nylon fabrics, using UV-curable Polyurethane acrylate Egypt. J. Rad. Sci. Applic., Vol. 28, No. 1-2 (2015) 
oligomer was investigated (El-Molla, 2007). The water repellency of the woven fabrics can be enhanced by the addition of vegetable oils (Ren et al., 2010). Also the antibacterial activities of the woven fabrics can be modified by using of $\mathrm{ZnO}$ as antibacterial agent (Zohdy, 1998).

The objective of this work is to satisfy multifunction finished (water retardant/antibacterial properties) fabric by applying epoxy acrylate oligomar formulation coat over cotton/polyester blend fabric and using castor oil as a plasticizer plus addition of $\mathrm{ZnO}$ as antibacterial agent. The coated fabric was also tested for pigment printing using the previous mentioned coating formulations as a printing paste in one single step. The relative ratio of castor oil to epoxy oligomer, $\mathrm{ZnO}$ concentration and pigment concentration were investigated to follow their effect on water retardant, antibacterial and colour intensity, respectively. Moreover, the mechanical and morphological properties were recorded to maintain a suitable reproducible usable formulation, which could satisfy the meant function with reasonable handling properties.

\section{Experimental}

\section{Materials}

EBECRYL 604, epoxy acrylate oligomer (EA) consisting of (80\% of bisphenol A epoxy diacrylate diluted with $20 \%$ of 1,6-hexanediol diacrylate) was obtained from Cytec Surface Specialties, Drogenbos, Belgium. Castor oil was supplied by Paint and Chemical Industry (PACHIN), Egypt. Benzophenone was supplied by Ciba Chemicals, Switzerland and used as a photoinitiator to initiate photochemical reaction during UV radiation process. Cotton/polyester plain weave blend fabric $\left(215 \mathrm{~g} / \mathrm{m}^{2}\right) 30: 70$, were kindly supplied by the Company for Textile, E-Mahalla, Egypt. The fabric were washed and scoured before usage. A fine powder of $\mathrm{ZnO}$ of analytical grade was kindly supplied by Prolabo (Prolabo, Cedex, France). Pigment dye, Bercolin orange B2R, was purchased from Bersa Textile Ve Kimya, Turkey. Genapol BE 2410 as non-ionic detergent was obtained by Clariant, Germany.

\section{Preparation of epoxy coating formulations}

EA and $\mathrm{CO}$ were mixed at different ratios with continuous stirring to get homogeneous mixtures to be used as formulations for coating (F1-F3) and 
formula F0 was used as blank and based on EA oligomer without any additives as indicated in Table 1. These formulations were then used as surface coated on the fabrics substrate by using film applicator with thickness of $\sim 100 \mu \mathrm{m}$. The coated fabrics were UV irradiated, as a curing source.

TABLE 1. The coating formulations used for coating of blend fabrics.

\begin{tabular}{|c|c|c|c|}
\hline \multirow{2}{*}{ Formulations } & \multicolumn{3}{|c|}{ Ingredients (\%) } \\
\cline { 2 - 4 } & Epoxy resin & Castor oil & Benzophenone \\
\hline F0 & 95 & 0 & 5 \\
\hline F1 & 70 & 25 & 5 \\
\hline F2 & 50 & 45 & 5 \\
\hline F3 & 30 & 65 & 5 \\
\hline
\end{tabular}

\section{UV irradiation of coated fabric}

UV Irradiation was carried out by using of UV lamp, EMITA VP-60 (made in Poland), with $180 \mathrm{~W}$ mercury lamp, 220V, $50 \mathrm{~Hz}$ equipped with monochromatic filter $(\lambda=320 \mathrm{~nm})$, installed at NCRRT, Egypt. The direct irradiation was used for inducing the curing process of coated cotton/ PET blend fabrics at constant distance $(50 \mathrm{~mm})$ from the lamp for various time intervals at a dose rate of $23.7 \mathrm{KJ} / \mathrm{m}^{2}$.

\section{Scanning Electron Microscope (SEM)}

SEM was used to identify the cross-section feature of the coated blend fibres, using JSM-640 Scanning Electron Microscope, JEOL (Japan) at 20MA and $30 \mathrm{KV}$. The dried samples were adjusted to liquid nitrogen, broken and then were sputter coated with gold using a microscope sputter coater and viewed through the microscope.

\section{Tensile mechanical testing}

The mechanical properties including tensile strength and elongation to break were determined at room temperature, according to the ASTM standard D5034 for textile fabrics. Rectangular specimens at diminutions of $40 \mathrm{~mm} \times 100$ $\mathrm{mm}$ were tested. Every data point is the average of 5 tests, (Mecmesin tester, Mecmesin Limited, UK), equipped with software was used and by employing a crosshead speed of $50 \mathrm{~mm} / \mathrm{min}$. In this system the different mechanical parameters were calculated directly.

Egypt. J. Rad. Sci. Applic., Vol. 28, No. 1-2 (2015) 


\section{Crease recovery measurements}

The ability of the coated fabric to resist and recover the deformation after releasing any load to the initial wrinkle free surface is expressed as crease recovery properties. The crease recovery of the fabric known to be measured by the angle between the pre folded halves, and is termed as the crease recovery angle. The crease recovery properties were determined in the dry and wet states of the fabrics, according to the ASTMD-1295-67 using a crease recovery tester model (METEFEM- Metrinpex) type FF-07 (Hungary).

The used load was $1 \mathrm{~kg}$ for $5 \mathrm{~min}$. at room temperature. The tested samples were cut according to a special standard rectangular shape. The recorded value of crease recovery angle is the average of five measurements.

\section{Water retardant properties}

The water retardance of the coated fabrics was tested by using two methods:

1-The water contact angle (WCA) of the deionized water drop, at ambient temperature was measured by using of the contact angle testing apparatus (Data Physics OCA 40, Data Physics Instruments, Germany). The average WCA value was determined by measuring three to five different positions of the same sample with $5 \mathrm{~mL}$ each time.

2-Evaluation of the water droplet behaviour over the tested samples over testing time is done by following these parameters; droplet deformation time, absorption time, diameter of droplet and number of wetted surface. Colour might be used in order to improve contrast during absorption. A stop watch was used to record the time of drop deformation and absorption time.

\section{Antibacterial and pigment coating of blend fabrics}

The blend fabrics were coated with the epoxy formulations (containing selected ingredient concentrations) with addition of different concentrations of $\mathrm{ZnO}$ as antibacterial agent and pigment dye as a colouring agent. The epoxy formulation was used as a paste for printing using the capsulation properties of epoxy. 


\section{Evaluation of the bacterial resistance of the coated fabrics}

Sterile nutrient agar medium was distributed in sterile Petri plates. 24 hours broth cultures of B. subtilis, and E. coli, containing $10^{8} \mathrm{CFU} / \mathrm{ml}$, were swabbed over the surface of nutrient agar plates using sterile cotton swab. The tested samples were cut into small pieces $\left(1 \mathrm{~cm}^{2}\right)$, and gently pressed on the swabbed agar surface. The plates were incubated at $37^{\circ} \mathrm{C}$ for $24 \mathrm{~h}$. The susceptibility of tested microorganisms was determined by measuring the surrounding inhibition zone. The experiment was performed in triplicates to ensure reproducibility.

\section{Colour measurements and durability of printing}

A computerized micro-colorimeter unit made by Dr. Lange (Germany) was used for color measurements. The $\mathrm{L}^{*}, \mathrm{a}^{*}$, and $\mathrm{b}^{*}$ system used is based on the CIE-Colour Triangle (Commission International De E' Clair Units X, Y, and Z). In this system, the $\mathrm{L}^{*}$ value represents the dark-white axis, $\mathrm{a}^{*}$ represents the green-red axis and $b^{*}$ represents the blue-yellow axis. The $\mathrm{L}^{*}, \mathrm{a}^{*}$, and $\mathrm{b}^{*}$ values of the different fabric, before treatment, were first measured and taken as references. The colour difference of the blend fabrics before and after coating process was calculated according to the following equation:

$$
\Delta \mathrm{E}^{*}=\sqrt{\left(\Delta L^{*}\right)^{2}+\left(\Delta a^{*}\right)^{2}+\left(\Delta b^{*}\right)^{2}}
$$

The durability of the coated blend fabrics against the repeated washing was investigated by using of the colour difference $\left(\Delta \mathrm{E}^{*}\right)$ measurements before and after repeating the washing with warm water $\left(40^{\circ} \mathrm{C}\right)$ for different times, in the presence of $1 \mathrm{~g} / 1$ non-ionic detergent. The tested washing cycles were 1,10 and 30 .

\section{Results and Discussions}

\section{Effect of the plasticizer concentration on the mechanical properties}

Fig. 1. shows the change in the tensile strength (MPa) and elongation percent at break for cotton/PET blend fabrics coated with different epoxy formulations containing different concentrations of $\mathrm{CO}$ as plasticizer, irradiated at constant dose of UV irradiation by exposing for $30 \mathrm{~min}$. It can be seen that, in general, the relation between tensile strength $(\mathrm{MPa})$ and elongation against Egypt. J. Rad. Sci. Applic., Vol. 28, No. 1-2 (2015) 
plasticizer per cent tends to be directly proportional up to $45 \% \mathrm{CO}$ thereafter the tensile strength tends to decrease.

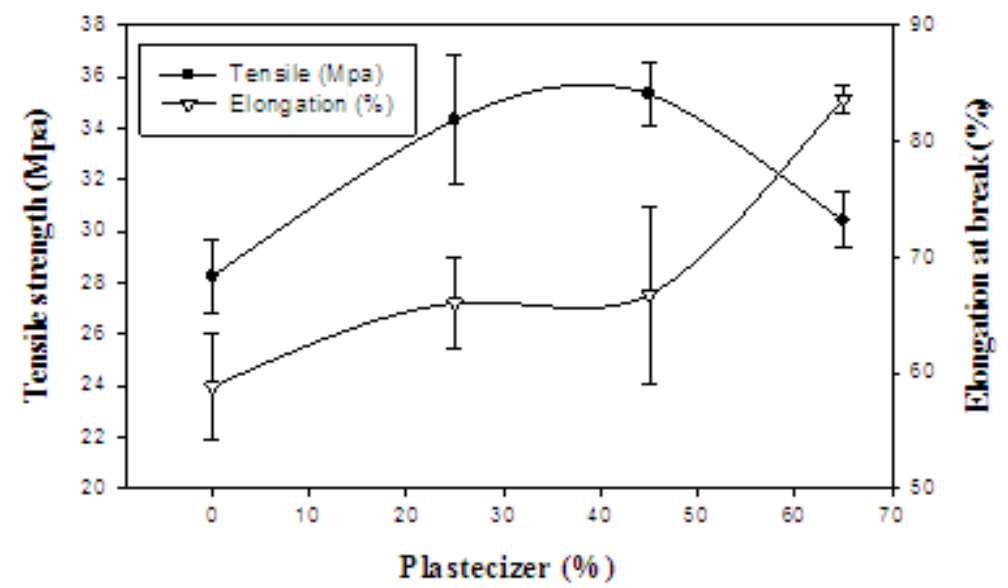

Fig. 1. Effect of plasticizer per cent on the mechanical properties of coated fabric with epoxy formulations.

\section{Effect of the plasticizer concentration on the crease recovery properties}

The effect of $\mathrm{CO}$ per cent on the crease recovery angle of the coated cotton/PET fabrics with epoxy formulations was shown in Table 2.

TABLE 2. Effect of plasticizers concentrations on the crease recovery properties of coated fabric with epoxy formulations.

\begin{tabular}{|c|c|c|}
\hline \multirow{2}{*}{ Treated blend fabric } & \multicolumn{2}{|c|}{ Crease recovery angle $\left({ }^{\circ} \mathrm{A}\right)$} \\
\cline { 2 - 3 } & Dry & Wet \\
\hline Uncoated fabric & $134 \pm 6$ & $118 \pm 3$ \\
\hline F0 coated fabric & 00 & 00 \\
\hline F1 coated fabric & $114 \pm 2$ & $107 \pm 7$ \\
\hline F2 coated fabric & $115 \pm 4$ & $115 \pm 2$ \\
\hline F3 coated fabric & $126 \pm 7$ & $120 \pm 4$ \\
\hline
\end{tabular}

It can be seen that the un-plasticized epoxy coated fabric broken easily due to its great hardness. On the other hand, the increasing of $\mathrm{CO}$ concentration lead to increasing of the crease recovery angle, which represents the increasing in the elasticity companied with decreasing in the toughness of the coated fabrics. From Fig. 1. \& Table 2. It can be concluded that the acceptable formulations from each plasticizer used were $\mathrm{F} 2$ at a concentration of (45\%) of $\mathrm{CO}$, which gives acceptable mechanical and crease recovery properties. As can be noted from the data, the epoxy coated F0 blend fabric records zero crease recovery 
due to the extreme hardness of the coated samples that cause instant break under the crease recovery test. This test proves undoubtedly the significant importance of plasticizer addition.

\section{Effect of $U V$ irradiation time on the mechanical properties}

Fig. $2 \&$ 3. show the change in the MPa and elongation at break (\%) for cotton/ PET blend fabrics coated with different epoxy formulations containing constant CO per cent of $45 \%$, irradiated with different times of UV irradiation.

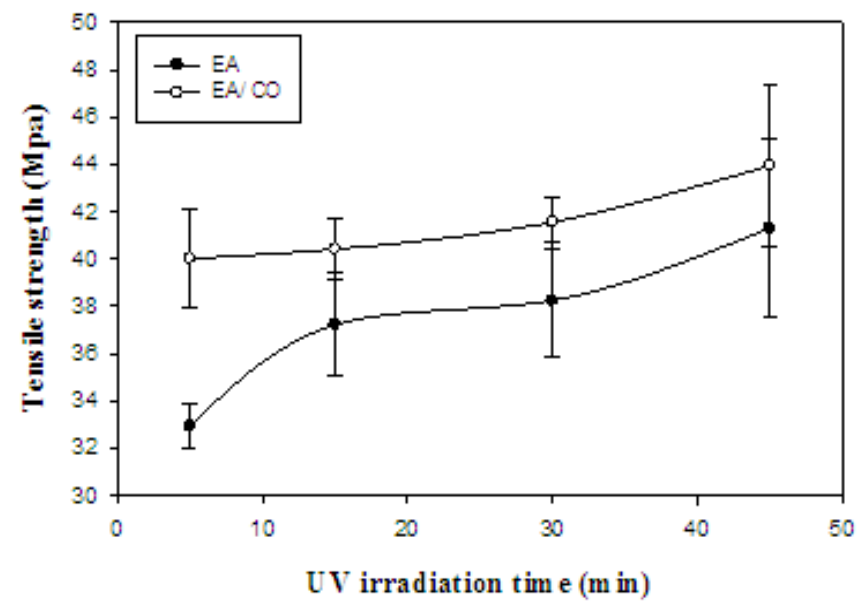

Fig. 2. Effect of UV irradiation time on the MPa of coated fabrics with epoxy formulation (F2).

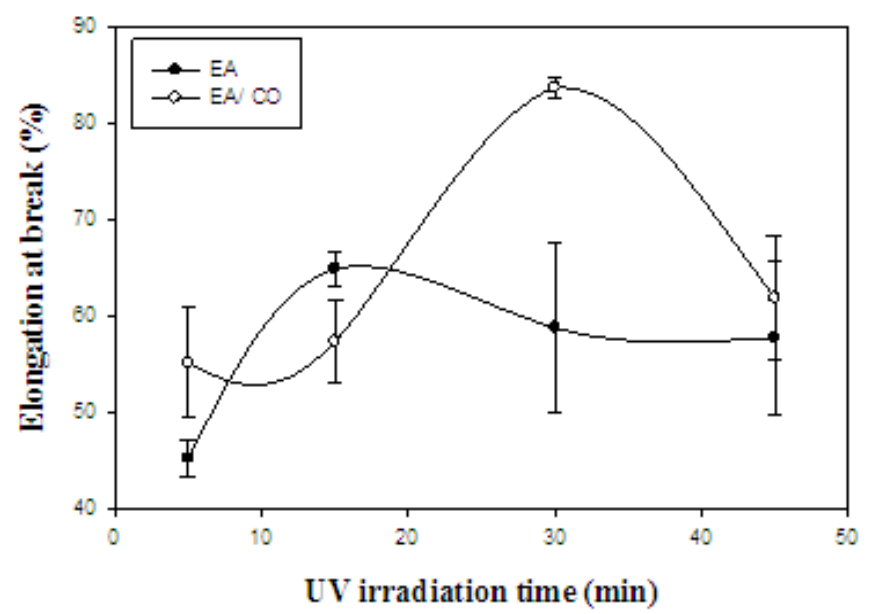

Fig. 3. Effect of UV irradiation time on the elongation at break (\%) of coated fabrics with epoxy formulation (F2).

Egypt. J. Rad. Sci. Applic., Vol. 28, No. 1-2 (2015) 
It can be seen that, in general, the MPa was increased by increasing of the UV irradiation time, accompanied with increasing in the elongation \% up to 30 $\min$. The further increasing in the irradiation time is lead to slightly increasing in the MPa with decreasing the elongation at break \%. This could be attributed to the increasing in the crosslinking formation of epoxy resin under radiation. It can be concluded that the acceptable irradiation dose is $30 \mathrm{~min}$.

\section{Effect of $U V$ irradiation time on the crease recovery properties}

The effect of UV irradiation time on the crease recovery angle for cotton/PET blend fabrics coated with different epoxy formulations containing $45 \% \mathrm{CO}$, comparing with un-plasticized formulation is shown in Table 3. It can be seen that the increasing of UV irradiation time lead to slightly decreasing in the crease recovery angle, as a result of the crosslinking effect of UV irradiation up on the epoxy formulations, which hinder the crease recovery angle. From the results in Fig. 2, 3 \& Table 3, it can be concluded that the acceptable UV irradiation time were $30 \mathrm{~min}$, which gave acceptable crease recovery and mechanical properties.

TABLE 3. Effect of UV irradiation time on the crease recovery properties of coated fabric with epoxy formulations.

\begin{tabular}{|c|c|c|c|c|}
\hline \multirow{2}{*}{ Irradiation time $(\min )$} & \multicolumn{3}{|c|}{ Crease recovery angles ('⿳⺈) of coated fabric } \\
\cline { 2 - 5 } & \multicolumn{2}{|c|}{ F0 } & \multicolumn{2}{c|}{ F2 } \\
\cline { 2 - 5 } & Dry & Wet & Dry & Wet \\
\hline $\mathbf{5}$ & $45 \pm 5$ & $52 \pm 7$ & $123 \pm 11$ & $121 \pm 9$ \\
\hline $\mathbf{1 5}$ & $32 \pm 4$ & $40 \pm 5$ & $118 \pm 10$ & $109 \pm 11$ \\
\hline $\mathbf{3 0}$ & 0 & 0 & $115 \pm 8$ & $98 \pm 5$ \\
\hline $\mathbf{4 5}$ & 0 & 0 & $97 \pm 8$ & $92 \pm 7$ \\
\hline
\end{tabular}

\section{SEM of the coated fabrics}

Fig. 4(a-c). shows the SEM micrographs of the fracture cross-section of uncoated and coated blend fabrics with EA and EA/CO. In Fig. 4(a), the free pull-out fibres of the fabric cross-section can be seen clearly. The crystalline fracture with good adhering and diffusion through the fibres cross-section, appears after coating with EA, which have good interfacial interaction with fabric fibrous, as seen in Fig. 4(b). By addition of CO to EA formulation, the crystalline appearance of the fracture cross-section was changed to semi amorphous, more roughness appearance and more diffusion thought the fabric fibrous as seen in Fig. 4(c). 


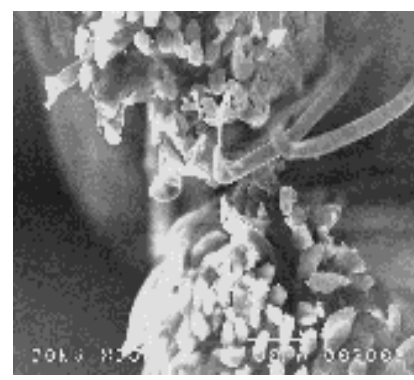

(a)

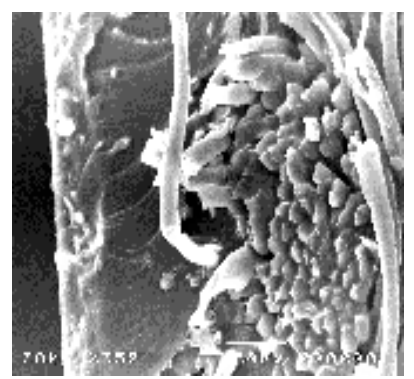

(b)

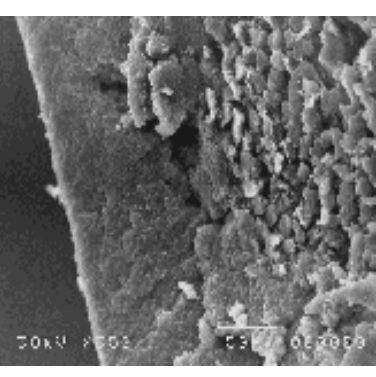

(c)

Fig. 4. SEM micrographs of the fracture cross-section of (a) uncoated fabric, (b) coated fabric with EA and (c) coated fabric with EA/ CO formulation.

\section{Water retardant of the coated fabrics}

The water repellency of the coated cotton fabric surfaces with EA and EA/ $\mathrm{CO}$ with $45 \% \mathrm{CO}, 5 \%$ benzophenone and cured by UV irradiation for $30 \mathrm{~min}$ were assessed with (WCA) measurements. In addition, the parameter for water droplets behaviour on a surface was also measured.

The data summarized in Table 4. shows that water repellency of the coated fabrics were improved by coating with EA, in which, the WCA gave $52^{\circ} \mathrm{A}$ as a result of the good water repellency of the hard crystalline EA coated film as seen in Fig. 5.

The photo shot was taken after 20sec upon deformation of the water droplet. Although, the $\mathrm{CO}$ possess high water repellency (Palanisamy et al., 2007), it was found that the WCA decreases slightly with increasing of the CO ratio in the EA formulation. This could be attributed to the effect of the surface morphology of the coated fabrics on the water surface tension (Gao et al., 2010). The addition of CO to the EA formulation changes the hard and crystalline appearance of the EA and the fabric coated surface exhibits the roughest morphology, which allow to some spreading to the water upon the coated surface. On the other hand, it can be seen that there no water diffusion from the upper to the lower surface of the coated fabrics after 10min, for all the tested coated samples, which indicates that the EA and EA/ CO have excellent water repellence properties.

Egypt. J. Rad. Sci. Applic., Vol. 28, No. 1-2 (2015) 


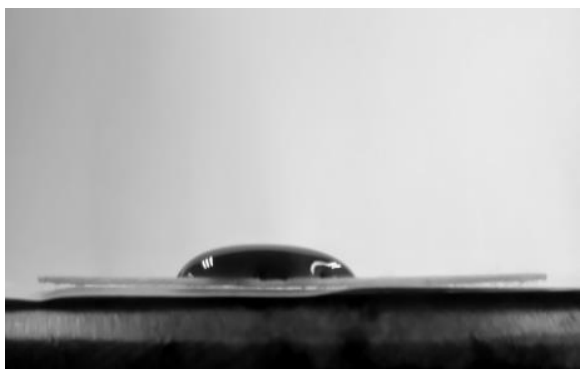

Fig. 5. Camera shot of water droplet on coated fabric after 10min.

TABLE 4. Effect of the different coated formulations on the water retardance parameters of the coated fabric.

\begin{tabular}{|c|c|c|c|c|}
\hline \multirow{2}{*}{ Samples } & \multicolumn{4}{|c|}{ Water retardance parameters } \\
\cline { 2 - 5 } & $\begin{array}{c}\text { WCA } \\
\left({ }^{\circ} \mathrm{A}\right)\end{array}$ & $\begin{array}{c}\text { Absorption } \\
\text { Time }(\mathrm{sec})\end{array}$ & $\begin{array}{c}\text { Diameter }(\mathrm{cm}) \\
\text { after 10min }\end{array}$ & Wet Surfaces \\
\hline Uncoated fabric & 0 & 20 & 2 & 2 \\
\hline F0 coated fabric & 52 & - & 0.6 & 1 \\
\hline F1 coated fabric & 49 & - & 0.6 & 1 \\
\hline F2 coated fabric & 46 & - & 0.7 & 1 \\
\hline F3 coated fabric & 45 & - & 0.8 & 1 \\
\hline
\end{tabular}

\section{Antibacterial properties of the coated fabrics}

The effect of the $\mathrm{ZnO}$ encapsulated concentration on the antibacterial properties of the coated cotton fabric with EA and EA/ $\mathrm{CO}$ at constant concentration of $45 \% \mathrm{CO}, 5 \%$ benzophenone, and cured by UV irradiation for $30 \mathrm{~min}$ were determined qualitatively against $B$. cereus and $E$. coli, as a function of the inhibition zone, was determined and recorded in Table 5.

TABLE 5. Effect of the $\mathrm{ZnO}$ concentration on the antibacterial properties of the coated fabrics.

\begin{tabular}{|c|c|c|c|c|c|}
\hline \multirow{2}{*}{ Microorganism } & \multicolumn{5}{|c|}{ Inhibition zone diameter (mm) } \\
\cline { 2 - 6 } & \multicolumn{5}{|c|}{ ZnO (\%) } \\
\cline { 2 - 6 } & $\mathbf{0}$ & $\mathbf{0 . 5}$ & $\mathbf{1}$ & $\mathbf{3}$ & $\mathbf{5}$ \\
\hline B. cereus & 0 & 0 & 0.2 & 0.3 & 0.4 \\
\hline E. coli & 0 & 0 & 0.1 & 0.1 & 0.2 \\
\hline
\end{tabular}

It was found that the antibacterial effect, reflected in the measured surrounding zone, was limited as a result of the capturing of $\mathrm{ZnO}$ in the epoxy coating formulation. However, by increasing the $\mathrm{ZnO}$ percentage the inhibition zone slightly increase against the tested bacteria. From the results, it can be concluded that $3 \% \mathrm{ZnO}$ is the most suitable percentage according to the antibacterial activity along with other physical properties of the coated fabrics.

Egypt. J. Rad. Sci. Applic., Vol. 28, No. 1-2 (2015) 


\section{Colour properties of the printed fabrics}

The data summarized in Table 6 represent the effect of the pigment per cent on the $\Delta \mathrm{E}^{*}$ of the coated cotton fabric with EA and EA/ CO at constant concentration of $45 \% \mathrm{CO}, 5 \%$ benzophenone, $3 \% \mathrm{ZnO}$ and cured by UV irradiation for $30 \mathrm{~min}$ and its durability against repeated washing cycles $(1,10$ and 30 cycles). As seen, the $\Delta \mathrm{E}^{*}$ increases by increasing of the pigment concentration. On the other hand, the durability of the coloured coated fabrics with EA/CO formulations was slightly decreased with increasing of the washing cycles, which could be attributed to the good encapsulating of the pigment dye through the cross linked EA/CO coated formulation upon the fabric surface. The $\Delta \mathrm{E}^{*}$ was found to decrease simultaneously by increasing both the washing cycles and the pigment per cent. As can be seen, $\Delta \mathrm{E}^{*}$ decreases by $17.7 \%$ compared to the unwashed sample after 30 washing cycles in case of $0.1 \%$ pigment per cent, while it decrease by about 19.3 in case of $1 \%$ pigment. However, the selected value for the pigment per cent as an optimum condition was $0.6 \%$ as the colour difference increase by 70.8 than $0.3 \%$ while $1 \%$ satisfies only $8.8 \%$ increase above the $0.6 \%$ pigment per cent.

TABLE 6. Effect of the pigment dye concentration on the wash fastness properties of coated fabrics.

\begin{tabular}{|c|c|c|c|c|}
\hline \multirow{2}{*}{ Pigment concentration $(\%)$} & \multicolumn{4}{|c|}{ colour difference $\left(\Delta \mathrm{E}^{*}\right)$} \\
\cline { 2 - 5 } & \multicolumn{4}{|c|}{ Washing cycles } \\
\cline { 2 - 5 } & None & $\mathbf{1}$ & $\mathbf{1 0}$ & $\mathbf{3 0}$ \\
\hline $\mathbf{0 . 1}$ & 12.4 & 12.1 & 11.8 & 10.2 \\
\hline $\mathbf{0 . 3}$ & 32.3 & 31.2 & 29.6 & 26.4 \\
\hline $\mathbf{0 . 6}$ & 55.2 & 52.2 & 50.1 & 45.1 \\
\hline $\mathbf{1}$ & 60.1 & 56.5 & 53.8 & 48.7 \\
\hline
\end{tabular}

\section{Conclusions}

This work was concerned with the surface coating of cotton/ PET fabrics with epoxy acrylate resin plasticized with castor oil, by using of UV irradiation as a curing system. In general, the addition plasticizer leads to the improving of the mechanical and crease recovery properties. In addition, the antibacterial properties of the coating formulations were improved via addition of $\mathrm{ZnO}$ as antibacterial agent. Moreover, the used formulation proved to be suitable a pigment paste, while the durability test gave adequate result after 30 washing 
cycles. Finally, the investigated coated blend fabric, as it satisfied multifunctional properties of antibacterial and water retardant plus good printing properties, it is recommended to be applied in tents, curtains and outdoor textile applications.

\section{References}

Bayramoglu, G., Kahraman, M. V., Apohan, N. K. and Güngor, A. (2006) Synthesis and characterization of UV-curable dual hybrid oligomers based on epoxy acrylate containing pendant alkoxysilane groups. Prog. Org. Coat., 57, 50.

Decker, C. (2003) Kinetic Study and New Applications of UV Radiation Curing. Macromol. Rapid Comm., 23, 1067.

El-Molla, M. M. (2007) Synthesis of polyurethane acrylate oligomers as aqueous UVcurable binder for inks of ink jet in textile printing and pigment dyeing. Dyes Pigments, 74, 371.

El-Naggar, A. M., Zohdy, M. H., Said, H. M., El-Din, M. S. and Noval, D. M. (2005) Pigment colors printing on cotton fabrics by surface coating induced by electron beam and thermal curing. Appl. Surf. Sci., 241, 420.

Gao, Y., He, C., Huang, Y. and Qing, F. L. (2010) Novel water and oil repellent POSS-based organic/inorganic nanomaterial: Preparation, characterization and application to cotton fabrics. Polymer, 51, 5997.

Ibrahim, M. S., Mohamed, H. A., Kandile, N. G., Said, H. S. and Mohamed, I. M. (2011) Steel protective coating based on plasticized epoxy acrylate formulation cured by electron beam irradiation. J. Rad. Res. Appl. Sci., 4, 59.

Landry, V., Riedl, B. and Blanchet, P. (2008) Nanoclay dispersion effects on UV coatings curing. Prog. Org. Coat., 62, 400.

May, C.A. (1988) Epoxy Resins: Chemistry and Technology. $2^{\text {nd }}$ ed., Marcel Dekker, New York, p. 278.

Mortley, A., Bonin, H.W. and Bui, V.T. (2007) Synthesis and properties of radiation modified thermally cured castor oil based polyurethanes. Nucl. Instrum. Meth. B, 265, 98 .

Oprea, S., Vlad, S., Stanciu, A. and Macoveanu, M. (2000) Epoxy urethane acrylate. Eur. Polym. J., 36, 373.

Palanisamy, A. and Rao, B. S. (2007) Photo-DSC and dynamic mechanical studies on UV curable compositions containing diacrylate of recinoleic acid amide derived from castor oil. Prog. Org. Coat., 60, 161.

Park, S. J. and Jin, J. S. (2001) Energetic studies on epoxy-polyurethane interpenetrating polymer networks. J. Appl. Polym. Sci., 82, 775.

Ren, Q. and Zhao, T. (2010) Synthesis and application of modified vegetable oils in water-repellent finishing of cotton fabrics. Carbohyd. Polym., 80, 381.

Egypt. J. Rad. Sci. Applic., Vol. 28, No. 1-2 (2015) 
Salimon, J., Salih, N. and Yousif, E. (2012) Industrial development and applications of plant oils, and their biobased oleochemicals. Arab. J. Chem., 5, 135.

Tabasum, S., Zuber, M., Jamil, T., Shahid, M. and Hussain, R. (2013) Antibacterial and pilling evaluation of the modified cellulosic fabrics using polyurethane acrylate copolymers. Int. J. Biol. Macromol., 56, 99.

Zohdy, M. H. (1998) Effect of Sandospace R on the dyeability of gamma-irradiated wool, wool/polyester and polyester fabrics with some disperse dyes containing amino groups. Polym Int., 47, 165.

(Received: 02/04/2015;

accepted: 02/08/2015)

Egypt. J. Rad. Sci. Applic., Vol. 28, No. 1-2 (2015) 


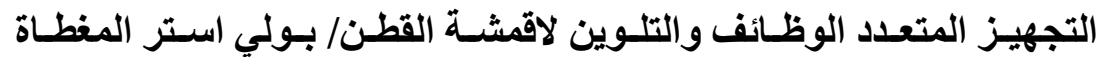

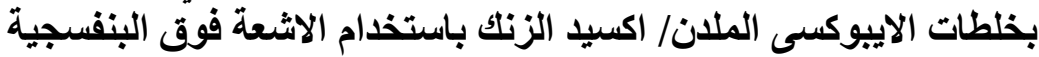

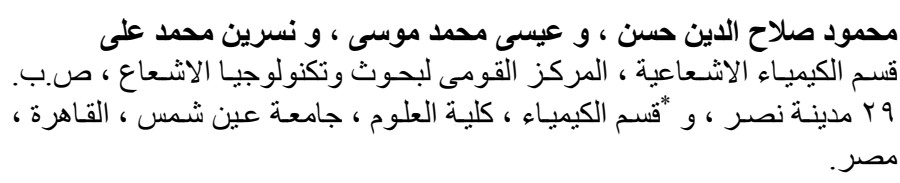

\begin{abstract}
تهدف الدر اسـة الى تحضير خلطات من الاييوكسى اكريلات الملدن

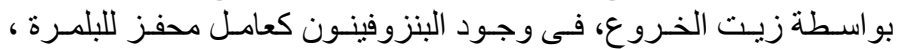

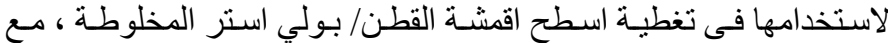

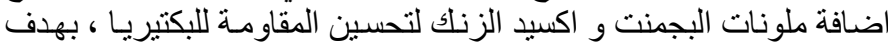

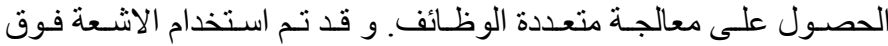

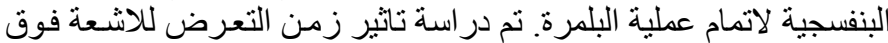

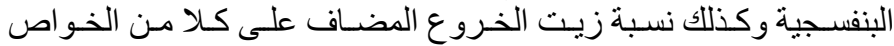

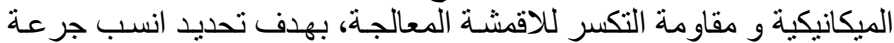

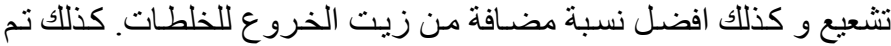

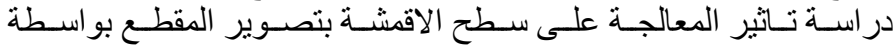

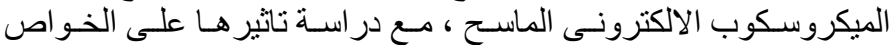

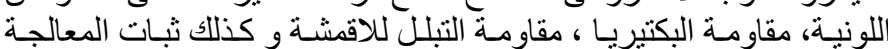
ل ل الغسيل المتكرر للاقمشة.

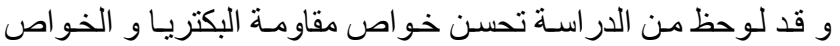

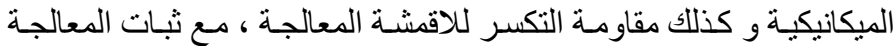

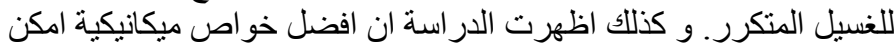

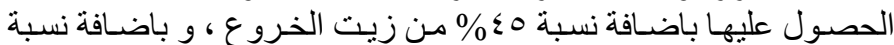

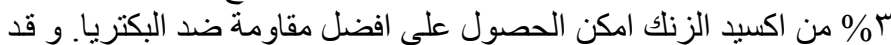

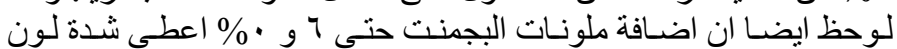
مناسبة و كذلك ثبات مقبول للغسيل المتكرر.
\end{abstract}

Egypt. J. Rad. Sci. Applic., Vol. 28, No. 1-2 (2015) 